\title{
Prevalence of bullying and aggressive behavior and their relationship to mental health problems among 12- to 15-year-old Norwegian adolescents
}

\author{
Anne Mari Undheim • Anne Mari Sund
}

Received: 16 February 2010/ Accepted: 23 August 2010/Published online: 3 September 2010

(C) The Author(s) 2010. This article is published with open access at Springerlink.com

\begin{abstract}
The aim of this study was to examine the relationships between being bullied and aggressive behavior and self-reported mental health problems among young adolescents. A representative population sample of 2,464 young Norwegian adolescents (50.8\% girls) aged 12-15 years was assessed. Being bullied was measured using three items concerning teasing, exclusion, and physical assault. Self-esteem was assessed by Harter's self-perception profile for adolescents. Emotional and behavioral problems were measured by the Moods and Feelings Questionnaire (MFQ) and the youth self-report (YSR). Aggressive behavior was measured by four items from the YSR. One-tenth of the adolescents reported being bullied, and 5\% reported having been aggressive toward others during the past 6 months. More of the students being bullied and students being aggressive toward others reported parental divorce, and they showed higher scores on all YSR subscales and on the MFQ questions, and lower scores on the global self-worth subscale (Harter) than students not being bullied or aggressive. A few differences emerged between the two groups being bullied or being aggressive toward others: those who were aggressive showed higher total YSR scores, higher aggression and delinquency scores, and lower social problems scores, and reported higher scores on the social acceptance subscale (Harter) than bullied students. However, because social problems were demonstrated in both the involved groups, interventions designed to improve
\end{abstract}

\footnotetext{
A. M. Undheim $(\bowtie) \cdot$ A. M. Sund

Norwegian University of Science and Technology,

Trondheim, Norway

e-mail: anne.m.undheim@ntnu.no
}

social competence and interaction skills should be integrated in antibullying programs.

Keywords Being bullied - Aggressive behavior - School · Adolescence $\cdot$ Mental health $\cdot$ Epidemiology

\section{Introduction}

Being bullied and aggressive behavior are serious problems that negatively affect schoolchildren's mental health and achievement [24]. Olweus [25] defines bullying or victimization in terms of being bullied, intimidated, or victimized when students are exposed, repeatedly and over time, to negative actions from more powerful peers. Such negative behavior may be manifested in various ways, for example, as teasing, active exclusion from a social group, or physical assaults [27].

In a cross-national study of 113,000 students between the ages of 11 and 15, from 25 countries, involvement in bullying (as being bullied or as being aggressive toward others) varied from 5 to $54 \%$ across countries [24, 27]. The estimates differ widely. Prevalence numbers for Norway are somewhat lower than for most countries [30].

Being bullied is known to be associated with a wide range of mental health problems. Victims are more anxious and insecure than other students, in general [25, 26]. The results of meta-analyses have shown victimization to be correlated with internalizing problems [15]. According to Perren and Alsaker [26], victimized children's lack of friends might render them psychologically and socially vulnerable, and thus more prone to becoming easy targets. In a Swedish study, a substantial proportion of the adolescents in the victim group showed psychiatric symptoms and functioned socially less well than students not involved 
as victims or as aggressive toward others (hereafter, "noninvolved" students) [18]. Nansel and colleagues [24] report remarkable consistency across countries on the relationships between bullying and psychosocial adjustment, with persons who bully others and victims both exhibiting poorer emotional adjustment than those who are not involved in such behaviors.

In general, individuals who are aggressive and bully others show externalizing symptoms [18], while findings concerning internalizing symptoms are less consistent [19]. The long-term effects of both being bullied and being aggressive in childhood are poor, and are reported to be potential risk factors for adolescent depression, suicidal behavior, and self-harm [8, 19, 20, 22, 31, 32]. A worrisome consequence for students who are aggressive toward others is susceptibility to future problems of violence and delinquency [28, 31].

Gender differences have been found in a cross-national study: boys reported higher rates of aggressive behavior in all 40 countries, and rates of victimization were higher for girls in 29 of 40 countries [11]. In a large Finnish study, each gender also had a different risk profile. Male victims were at risk of anxiety and later suicide attempts and suicide, and aggressive males were at risk of personality disorders. However, an aggressive status did not predict any psychiatric outcomes or suicidal behavior when psychiatric problems in year 8 were controlled. Among girls, frequent victimization predicted suicide attempts and suicides even when problem levels at 8 years of age were controlled for [20, 22].

In the present study, in contrast to other studies, specific questions about being bullied both at school and on the way to school were included, in addition to assessment of levels of being bullied. Being aggressive toward others was measured by a scale constructed of four items, while other studies often use a single question. The present study focused the social behavior of the adolescents, their social acceptance, their self-esteem as well as their mental health status, to examine characteristics of bullied and aggressive students. Social problems represented by extreme shyness and related characteristics are suggested as a first step to harassment [13] and were assessed and discussed in the present study, something that has seldom been done in earlier research. Although children involved as victims or as aggressive are more likely to have used mental health services at some time during their lives [21], the use of mental health services for such problems might also differ across countries.

The aims of this study were to assess the prevalence of being bullied and behaving aggressively toward others and the psychosocial characteristics of exposed students, and to make comparisons with noninvolved students. In addition, the help-seeking behaviors of affected students were addressed, and differences between genders were explored.

\section{Methods}

Procedure

The present study was conducted as part of the Youth and Mental Health Study, a longitudinal study assessing mental health among adolescents aged 12-15 years in two counties in central Norway, including one large city, at two time points $\left(T_{1}\right.$ and $\left.T_{2}\right), 1$ year apart, between 1998 and 2000 . Twenty-two schools were selected with a probability proportional to their size. A cluster sampling procedure using schools as sampling units was chosen, stratified according to urbanity and geography. The nonresponders $(n=327)$ at the first data collection were significantly more likely to be boys $\left[\chi^{2}(1)=45.0, P<0.001\right]$ and younger adolescents $\left[\chi^{2}(1)=5.47, P<0.05\right]$. Written consent was obtained from the adolescents and their parents. The questionnaires were completed during two consecutive school hours. Data from the $T_{1}$ data collection were used in the present study.

Initial sample $\left(T_{1}\right)$

The $T_{1}$ sample consisted of 2,464 adolescents, $50.8 \%$ of whom were girls with a mean age of 13.7 (range 12.5-15.7, SD 0.58). The response rate was $88.3 \%$.

\section{Measures}

\section{Demographics}

Socioeconomic status (SES) of the parents was measured by the classification of the mother's and father's occupations according to the ISCO-88 guidelines [17]. An ordinal scale ranging from 1 (highest) to 5 (lowest) was made. A total of 93.4\% of participants had both parents born in Norway, $3.9 \%$ had one parent born in Norway and one parent born in another country, and $2.7 \%$ had both parents from another country. For analysis, a dichotomized variable was made (one or two Norwegian parents vs. nonNorwegian parents). Of the final sample, $26.9 \%$ of participants reported having divorced parents. Of these around 50\% lived with single mothers, $36 \%$ with stepmothers, $9 \%$ with single fathers and the rest shared time between mother and father or lived with foster parents.

\section{Being bullied}

Being bullied was measured by three items concerning teasing, exclusion, and physical assault [3], each rated on a 0 - to 5-point scale from "never" to "more than three times a week" during the past 6 months, in school or on the way to school. The following items were used: "I am being 
made a fool of, teased in a painful way, or somebody has said mean things to me" (teasing); "Sometimes somebody is intentionally excluded by fellow students, or somebody is not allowed to come along. Has such a thing also happened to you?" (exclusion); and "I am tormented, beaten, pulled by the hair, kicked, or attacked in a bad way" (physical assault). These items have previously been used in Norwegian studies [2,3]. The total sum score on the being bullied scale was determined; this ranged from 0 to 15. The scale has good internal consistency, with a Cronbach's alpha coefficient of 0.68. A dichotomized variable was constructed, including students who were exposed once a week or more ("frequently") during the past 6 months to any of the items versus students who had not reported being bullied or had reported being bullied only once or twice during the past 6 months, consistent with the cutoff made by Roland [27].

\section{Aggressive behavior toward others}

A composite scale was constructed from four items from the Youth Self-Report (YSR) [1] that describe aggressive behavior: "I treat others badly"; "I physically attack people"; "I tease others a lot"; and "I threaten to hurt people". The time range was the previous 6 months. No specific attempts were made to make the students aware that these items could represent a bullying focus. Each item was rated on a $0-2$ scale: $0=$ "not true"; $1=$ "somewhat or sometimes true"; $2=$ "very true or often true". A total sum score was determined. This scale ranged from 0 to 8 . The internal consistency of the scale was 0.69 . The variable was dichotomized to "often" versus "not true or sometimes" being aggressive toward others during the past 6 months on any of the items.

\section{Emotional and behavioral problems}

The YSR [1] is a widely used self-reporting measure for assessing social competence and mental health problems among adolescents aged 11-18 years. A Norwegian version of the YSR was used to assess students' psychosocial problems [23]. The YSR consists of 103 problem items rated on a 0 - to 2-point scale: $0=$ "not true"; 1 = "somewhat or sometimes true"; 2 = "very true or often true". The time range was the past 6 months. The YSR consists of nine subscales, and all of the subscales were used in the present study. The social problem subscale included items like "I act too young for my age," "I am not liked by other kids," "I keep from getting involved with others," and "I am too dependent on adults".

The instrument had construct validity and good testretest reliability [1]. In the present study, a Cronbach's alpha of 0.89 on the sum score scale was found. The alpha values for the seven subscales ranged from 0.65 to 0.86 (except for withdrawn, 0.57, and social problems, 0.58). Participants who omitted more than eight items on the YSR were excluded from the analyses, in accordance with the manual instructions; this excluded $10.9 \%$ of the adolescents.

\section{Depressive symptoms}

The Moods and Feelings Questionnaire (MFQ) is a 34-item questionnaire designed for children and adolescents aged 8-18 years, who report depressive symptoms as specified by the DSM-III-R diagnostic system [5]. The individual is asked to report on his or her feelings during the preceding 2 weeks on a 3-point scale ("not true", "sometimes true", and "true"). The total score range is $0-68$. High scores represent high depressive symptom levels. In the present sample, 3-week and 2-month test-retest reliabilities have been reported to be $r=0.84$ and $r=0.80$, respectively [33], while internal consistency was alpha $=0.91$, and convergent validity with the Beck depression inventory was $r=0.91$. The MFQ has been validated using clinical samples [12, 36].

\section{Self-esteem}

Self-esteem was measured using a revised version of The self-perception profile for adolescents (SPPA) $[14,35]$. The SPPA consists of several subscales. Each domain is measured by five items and is scored on a 4-point scale from "applies very well" to "applies very badly". In this study, the three following subscales were included: global selfworth, social acceptance, and physical appearance. Internal consistencies, as assessed by Cronbach's alpha, for the subscales global self-worth and social acceptance were 0.80 and 0.89 for the subscale physical appearance. High mean item scores represent high self-esteem on the three scales (range 1-4).

\section{Number of close friends}

This was measured by a single question with four different alternatives (none, one, two-three, four or more close friends) and was treated as an ordinal variable in the analyses.

\section{Help-seeking behavior}

The adolescents were asked if they had received help for mental health problems (from teachers, counselors, school nurses, medical practitioners, psychologists, or psychiatrists) during the past year (No/Yes). 
Statistical analyses

The three groups, being bullied, aggressive toward others and noninvolved students were studied. On the various scales (except YSR, which in accordance with manual instructions excluded when omitting more than 8 items), those who had omitted more than $10 \%$ of the items were removed from the analyses. Otherwise, missing values were replaced by the mean item scores. Data were analyzed using the Statistical Package for the Social Sciences (SPSS, ver. 16, Chicago, IL). Relationships between categorical variables were analyzed by Pearson's $\chi^{2}$ statistics. Differences between group means were estimated using $t$ tests or one-way ANOVA with Bonferroni post hoc tests. For searching interactions with gender, two-way ANOVAs were performed. For ordinal variables, Mann-Whitney $U$ and Kruskal-Wallis tests were used. Before all analyses, the items from the YSR constituting the aggressive behavior toward others scale were removed from the YSR scales to prevent redundancy. Using the dichotomized bullying variable, a grouping variable including numbers of students being bullied, aggressive toward others, and noninvolved was constructed for frequencies and ANOVA analyses. Students being both bullies and victims (bullyvictim) were excluded from the analyses because of small numbers $(n=8)$. A significance level of $P<0.05$ was used.

\section{Results}

Prevalence of being bullied and aggressive behavior toward others

Ten percent ( $n=240$ ) of adolescents reported being bullied once a week or more frequently; $8 \%$ reported being teased, $3.5 \%$ reported being excluded, and $1.9 \%$ reported physical assault in the same period. Some reported having been exposed to more than one type of behavior. Significantly more boys than girls reported physical assault once a week or more frequently ( 2.6 vs. $1.3 \%$ ), [ $\left.\chi^{2}(1)=5.4, P<0.05\right]$. No gender difference was found for teasing and exclusion, see Table 1.

Five percent of the adolescents reported having been aggressive toward others "often" during the past 6 months. Often teasing others was reported by $1.6 \%$, attacking others by $1.8 \%$, threatening others by $1.5 \%$, and being mean to others by $1.8 \%$. Significantly more boys than girls reported frequent aggression toward others on the items examined $\left[6.9\right.$ vs. $\left.3.2 \%, \chi^{2}(1)=16.9, P<0.001\right]$, see Table 2 for a list of frequencies of aggression items toward others by gender.

\section{Relationships between psychosocial measures}

The being bullied scale correlated with all the YSR subscales from 0.18 to $0.42(P<0.01)$. The social problem scale correlated most strongly with the being bullied scale

Table 1 Victims of bullying

\begin{tabular}{|c|c|c|c|c|c|c|}
\hline & \multicolumn{2}{|l|}{ Teased (\%) } & \multicolumn{2}{|l|}{ Excluded $(\%)$} & \multicolumn{2}{|c|}{ Physical assault (\%) } \\
\hline & $\begin{array}{l}\text { Boys } \\
(n=1,212)\end{array}$ & $\begin{array}{l}\text { Girls } \\
(n=1,252)\end{array}$ & $\begin{array}{l}\text { Boys } \\
(n=1,212)\end{array}$ & $\begin{array}{l}\text { Girls } \\
(n=1,252)\end{array}$ & $\begin{array}{l}\text { Boys } \\
(n=1,212)\end{array}$ & $\begin{array}{l}\text { Girls } \\
(n=1,252)\end{array}$ \\
\hline Not in past 6 months & 62.0 & 61.7 & 75.3 & 70.0 & 81.8 & 90.6 \\
\hline $1-2$ times in past 6 months & 26.8 & 27.5 & 17.6 & 23.7 & 11.4 & 5.3 \\
\hline Once a week & 4.1 & 4.1 & 1.3 & 1.7 & 1.7 & 0.3 \\
\hline 2-3 times a week & 1.5 & 2.6 & 0.8 & 0.9 & 0.5 & 0.8 \\
\hline More often & 1.8 & 1.8 & 1.0 & 1.2 & 0.4 & 0.2 \\
\hline
\end{tabular}

Percentages of boys and girls having been teased, excluded, and physically assaulted during the past 6 months in school or on the way to school Because of missing values, the total sum of percentages is different from $100 \%$

Table 2 Aggressive behavior toward others: Percentages of adolescents reporting aggressive behavior toward others on the YSR during the past 6 months

\begin{tabular}{|c|c|c|c|c|c|c|c|c|}
\hline & \multicolumn{2}{|c|}{ Mean to others $(\%)$} & \multicolumn{2}{|c|}{ Attacking others (\%) } & \multicolumn{2}{|c|}{ Teasing others $(\%)$} & \multicolumn{2}{|c|}{ Threatening others (\%) } \\
\hline & $\begin{array}{l}\text { Boys } \\
(n=1,211)\end{array}$ & $\begin{array}{l}\text { Girls } \\
(n=1,248)\end{array}$ & $\begin{array}{l}\text { Boys } \\
(n=1,211)\end{array}$ & $\begin{array}{l}\text { Girls } \\
(n=1,248)\end{array}$ & $\begin{array}{l}\text { Boys } \\
(n=1,211)\end{array}$ & $\begin{array}{l}\text { Girls } \\
(n=1,248)\end{array}$ & $\begin{array}{l}\text { Boys } \\
(n=1,211)\end{array}$ & $\begin{array}{l}\text { Girls } \\
(n=1,248)\end{array}$ \\
\hline Not true & 70.3 & 82.5 & 73.8 & 88.5 & 71.7 & 83.5 & 77.0 & 90.8 \\
\hline Sometimes true & 24.4 & 15.1 & 19.7 & 8.5 & 19.1 & 11.8 & 13.1 & 4.6 \\
\hline Often true & 2.6 & 1.0 & 2.8 & 0.9 & 2.2 & 1.0 & 2.4 & 0.6 \\
\hline
\end{tabular}

Because of missing values, the total sum of percentages is different from $100 \%$ 
Table 3 Mean values and SDs (in parentheses) for the various scales for being bullied (once a week or more), aggressive toward others "often", and noninvolved adolescents with Bonferroni post hoc tests $(n=2,464)$

\begin{tabular}{|c|c|c|c|c|c|}
\hline & $\begin{array}{l}\text { Being bullied } \\
(n=224)\end{array}$ & $\begin{array}{l}\text { Aggressive toward } \\
\text { others }(n=97)\end{array}$ & $\begin{array}{l}\text { Noninvolved } \\
(n=1914)\end{array}$ & $\begin{array}{l}\text { Group } \\
\text { difference }(F)\end{array}$ & $\begin{array}{l}\text { Post hoc } \\
\text { comparison }\end{array}$ \\
\hline MFQ (0-68) & $17.3(11.4)$ & $15.5(12.0)$ & $9.5(8.6)$ & $90.1 * * *$ & $3<1,2 * * *$ \\
\hline Global self-worth (1-4) & $2.7(0.7)$ & $2.8(0.7)$ & $3.1(0.6)$ & $56.5 * * *$ & $3>1,2 * * *$ \\
\hline Social acceptance (1-4) & $2.6(0.6)$ & $3.1(0.6)$ & $3.2(0.5)$ & $140.1 * * *$ & $\begin{array}{l}1<2,3^{* * *} \\
2>1 * *\end{array}$ \\
\hline YSR sum score scale (0-192) & $47.1(22.7)$ & $54.5(28.5)$ & $30.1(17.2)$ & $147.0 * * *$ & $\begin{array}{l}3<1,2 * * * \\
2>1 * *\end{array}$ \\
\hline Withdrawn (1-12) & $4.1(2.3)$ & $4.1(2.8)$ & $2.7(2.0)$ & $53.9 * * *$ & $1,2>3 * * *$ \\
\hline Somatic (1-15) & $4.2(3.2)$ & $3.6(3.5)$ & $2.5(2.6)$ & $40.9 * * *$ & $\begin{array}{l}1>3 * * * \\
1>2 * *\end{array}$ \\
\hline Anxious/depressed (1-29) & $9.0(6.1)$ & $7.9(6.2)$ & $4.4(4.2)$ & $114.0 * * *$ & $1,2>3 * * *$ \\
\hline Social problems (1-12) & $4.1(2.6)$ & $3.5(2.9)$ & $2.0(1.7)$ & $137.1 * * *$ & $\begin{array}{l}1,2>3^{* * *} \\
1>2^{*}\end{array}$ \\
\hline Thought problems (1-12) & $2.5(2.3)$ & $3.0(2.8)$ & $1.6(2.0)$ & $36.2 * * *$ & $1,2>3 * * *$ \\
\hline Attention problems (1-18) & $6.0(3.3)$ & $6.1(3.7)$ & $4.0(2.7)$ & $66.0 * * *$ & $1,2>3 * * *$ \\
\hline Delinquent problems $(1-19)$ & $3.6(2.9)$ & $6.3(4.4)$ & $2.7(2.2)$ & $106.4 * * *$ & $\begin{array}{l}1,2>3 * * * \\
2>1 * * *\end{array}$ \\
\hline Aggressive problems (1-31) & $8.9(4.4)$ & $11.1(5.3)$ & $6.8(3.8)$ & $72.8^{* * *}$ & $\begin{array}{l}1,2>3 * * * \\
2>1 * * *\end{array}$ \\
\hline Self-destructive (1-20) & $4.5(3.4)$ & $5.0(4.1)$ & $2.0(2.3)$ & $136.3 * * *$ & $1,2>3 * * *$ \\
\hline
\end{tabular}

No gender interaction was found

$n s$ not significant

*** $P<0.001, * * P<0.01, * P<0.05$

( $r=0.42, P<0.01$ ). The YSR subscales also correlated with the aggression toward others scale from 0.20 to 0.56 $(P<0.01)$. The YSR delinquent behavior scale followed by the aggressive behavior scale correlated most strongly with the aggressive behavior toward other scale $r=0.56$ $(P<0.01)$, and $r=0.51(P<0.01)$, respectively.

Differences between groups on demographics

No significant differences in SES levels and ethnicity across the three groups were found. More of the students being bullied and students being aggressive toward others reported parental divorce than did noninvolved students [34.1 and $39.6 \%$ vs. $\left.26.3 \%, \chi^{2}(2)=14.26, P<0.01\right]$; however, no significant difference was seen between the two involved groups. Students being bullied reported having fewer friends than the other two groups $\left[\chi^{2} \quad(2)=71.11\right.$, $P<0.001]$, which did not differ from each other.

Differences between groups on emotional and behavioral problems

Using the grouping variables, one-way ANOVA showed differences between the three groups (being bullied, being aggressive toward others, and noninvolved). Mean values, SDs, and group differences for the variables are shown in Table 3.

The ANOVA analyses showed no differences in depression levels between students being bullied and students being aggressive toward others; however, both groups reported significantly higher levels than noninvolved students $(P<0.001)$. Similar group differences were also found on the global self-worth subscale. On the YSR, students being bullied and students being aggressive toward others showed significantly higher scores than noninvolved students on all subscales $(P<0.001)$.

However, differences between the being bullied and the aggressive students were found. Students being aggressive toward others showed significantly higher scores on the YSR sum score scale $(P<0.001)$ and delinquent and aggressive behavior scales $(P<0.001)$, and lower scores on social problems $(P<0.05)$, than students being bullied. Students being aggressive toward others reported higher social acceptance than students being bullied.

Although gender differences were found in the whole sample, no two-way interactions were found between the being bullied and the aggressive groups on the MFQ, the YSR (including all subscales), the social acceptance or global self-worth scales, or gender. 
Help and support

Almost $15 \%$ of adolescents who were bullied "frequently", $13.8 \%$ of students who were being aggressive toward others "often", and only $3.7 \%$ of noninvolved students had received help because of mental health problems during the past year. Both involved groups were significantly $\left[\chi^{2}(2)=61.5, P<0.001\right]$ different from noninvolved students, but not from each other. Gender differences were found: bullied boys got more help than bullied girls (16.3 vs. 13.6\%); however, no gender differences among the aggressive students were shown (both 13.8\%). Among girls, there were no differences in receiving help between bullied and aggressive students, while among boys, the rate was higher among bullied than aggressive students [16.3 vs. $\left.13.8 \%, \chi^{2}(2)=46.90, P<0.001\right]$.

\section{Discussion}

\section{General trends}

In the present study, the relationships of being bullied and aggressive behavior to psychosocial problems among young Norwegian adolescents were examined. About 10\% of the adolescents reported frequently being bullied during the past 6 months. This finding is consistent with earlier research [18]. The prevalence of aggressive behavior toward others was somewhat higher than in similar studies. Assessing aggressive behavior instead of bullying might cause a higher prevalence rate. The family situation was related to aggressive behavior. Not living with both biological parents might leave the adolescents vulnerable in many ways: less monitoring, often fewer adults to confide in, and sometimes increased aggression because of feelings of loss might contribute. Likewise, adolescents living with single parents or in step families also face certain challenges that might influence their emotional wellbeing. Adolescence is generally a particular sensitive period for family problems [29].

Both bullied adolescents and adolescents who were aggressive toward others showed lower global self-worth, higher levels of depressive symptoms, and more broadspectrum psychological problems than noninvolved adolescents. These findings are consistent with earlier reports [18, 19, 24]. Low self-worth, frequently reported by depressed students, might both be a cause and a result of being bullied or being aggressive. Bullied adolescents' feelings of being less socially accepted by peers might weaken their ability to fight for their positions in school or in peer groups and therefore make them more prone to becoming easy targets [26]. According to Dill et al. [13] the contribution of shyness/social withdrawal in predicting negative affect could be explained by the effect of peer rejection/social difficulties on negative affect, which was then mediated by the experience of actual victimization.

In the present study, the adolescents who were aggressive toward others also reported a wide array of conduct problems, and they showed higher levels of depressive, aggressive, and delinquent behaviors than noninvolved students, consistent with earlier findings [31]. Aggressive behavior is one of the criteria of conduct disorder in the DSM-IV [4].

Although those who are bullied and those who are aggressive toward others both have high levels of various problems, the groups differ in significant ways. Externalizing problems (delinquency and aggression) dominated among adolescents who were aggressive toward peers, consistent with earlier findings [18], while anxious/depressed symptoms dominated among those who were bullied. However, both groups involved as being bullied or aggressive reported higher levels of social problems than noninvolved peers. The social problems seen in both the bullied and the aggressive adolescents reflect difficulties in socializing with same-age peers. This is important to note because friends and peer groups play a very important role in teenagers' lives.

Students who were aggressive toward others and noninvolved students reported higher social acceptance than students being bullied. These findings are not so often reported in earlier studies. However, the findings might be in line with Thunfors and Cornell's [34] study where aggressive students are among the most popular students in middle school. According to their study students may be disliked, but still regarded as popular. The relationship between aggression and popularity is also reported by Bowker and colleges [10] suggesting that aggressive and other antisocial behaviors may reflect attempts to re-establish and gain new status in new peer context. Middle school transition was important for gaining new status in the Bowker study, and respondents in the present study just left elementary school and entered junior high school.

\section{Gender}

More boys than girls reported having experienced physical assaults supporting earlier results [11], but no other gender differences were found. Teasing and exclusion more often associated with girls' behavior [9] was not demonstrated in the present study. It could be that both boys and girls are more engaging in more of all forms of bullying and aggressive behavior. This is supported by Craig and colleges [11] in a recent study. Their finding was relatively consistent across age and countries. A review paper [9] also reports on studies where boys outnumber girls in every kind of aggressive behavior. Because physical assault is often 
easier to detect than teasing and exclusion, the boys' problems might thus be easily noticeable by adults while girls indirect bullying is more difficult to detect. Higher rates of depressive symptoms have been consistently reported among girls in this age group [6,33]. Being bullied might be a hidden factor contributing to such symptoms.

That boys in our study were more often involved in aggression toward others is in line with other findings [11, 30]. Being bullied and being aggressive showed, however, no interactional gender-specific effect in this crosssectional study with regard to mental health problems. Victimized girls were not more affected than victimized boys, neither on internal nor on external problems, which is at odds with findings from other studies [19]. That boys have similar risk for depression as girls is important and not so much focused earlier. One explanation is that boys and girls are getting more similar these days including their reactions toward stressful situations. The findings, however, support a recent study from the Netherlands [7] reporting no gender differences in mental health problems as a result of peer victimization, suggesting that being rejected by peers at school is a universal stressor during early adolescence.

\section{Help-seeking behavior}

It is noteworthy that students in the present study being bullied and students showing aggressive behavior received help because of mental health problems at almost equivalent rates. Overall, low rates of help-seeking behavior were found in both these groups, despite elevated levels of mental health problems. The rates were much lower than contact with mental help professionals reported by Kumpulainen et al. [21]. However, these students were younger and still attending elementary school. Available services for students in the present study might not offer help that is specific enough for these groups, thus discouraging the adolescents from seeking help. Further, students need to see the situation as one in which something can be achieved in order to seek help [16]. Student in the present study might not have had the same trust in their teachers or local help agencies to do so. They are new in junior high school and might not know their counselors well enough or they might be afraid of being tattlers.

\section{Prevention}

School and health personnel should be aware of being bullied and aggressive behavior as a possible hidden factor behind social and emotional problems. Students involved as victims or aggressors should be given more attention and encouraged to visit appropriate services. Active attempts to promote inclusion and friendships for shy and socially withdrawn children during the early elementary school years might be a crucial intervention in preventing victimization [13]. However, antibullying prevention programs have varied greatly in their outcomes. While Olweus [25] reported success in Norway, other studies have reported more moderate results [28].

Strengths and limitations

The strengths of this study are its large representative sample, high response rate $(88.3 \%)$, and use of standardized self-report measures of mental health problems. Overall, there were few missing data, although about $11 \%$ of the adolescents omitted more than eight items on the YSR and were excluded from the analyses. These might be adolescents more involved as victims or aggressors than others, and this may therefore weaken the results. The study includes adolescents who have not yet reached the age when school dropout is considered a serious problem, and therefore it represents the student population, in general. Being bullied was measured by three questions, compared with only one in most studies; however, not all areas important in youth cultures today, such as cyber bullying, were covered.

Limitations of the study are its use of just one geographical region in Norway with only one moderately sized city, and the participants' restricted age range. All measures used were self-report instruments, and no complementary source of information, for example, from teachers or parents, was included. Being bullied and aggressive behavior often occurs when parents or teachers are not around, and most children are cautious of disclosing such events. Selfreports are therefore likely to be a reliable source on these matters [9]. The items concerning aggression toward others included different aspect of victimization, both direct and nondirect, verbal and nonverbal and might tap a broader range of behavior than bullying traditionally does. The items did not specifically assess behavior toward other adolescents, so other types of aggressive behavior might also be included in the participants' answers. Lastly, in this cross-sectional study, we cannot make any inferences about the causality of the relationships.

\section{Conclusion}

More than $10 \%$ of adolescents reported having been bullied once a week or more frequently, and $5 \%$ of the students reported having been aggressive toward others often during the past 6 months. Bullied students and students who were aggressive toward others showed significantly higher scores on all YSR subscales, higher depressive symptom scores, and more often had divorced parents than 
noninvolved students. Bullied students reported significantly lower social acceptance and fewer friends than both students who were aggressive and noninvolved students. Social problems were demonstrated in both involved groups. Interventions aimed at improvement of social competence and interaction skills are therefore needed and should be integrated in antibullying programs. However, low rates of help-seeking behavior among adolescents in both involved groups were found, indicating how hard those adolescents are to reach.

Acknowledgments This study was supported by grants from the Research Council of Norway and from the National Council for Mental Health, Norway.

Open Access This article is distributed under the terms of the Creative Commons Attribution Noncommercial License which permits any noncommercial use, distribution, and reproduction in any medium, provided the original author(s) and source are credited.

\section{References}

1. Achenbach TM (1991) Integrative guide for the $1991 \mathrm{CBCL} / 4$ 18, YSR, and TRF profiles. University of Vermont, Department of Psychiatry, Burlington

2. Alsaker FD, Brunner A (1999) Switzerland. In: Smith PK, Morita Y, Junger-Tas J, Olweus D, Catalano R, Slee PT (eds) The nature of school bullying: a cross-national perspective. Routledge, London, pp 250-263

3. Alsaker FD (2003) Quälgeister und ihre Opfer. Mobbing unter Kindern-und wie man damit umgeht. Huber Verlag, Bern

4. American Psychiatric Association (1994) Diagnostic and statistical manual of mental disorders, 4th edn. APA, Washington, DC

5. Angold A (1989) Structured assessment of psychopathology in children and adolescents. In: Thompson $\mathrm{C}$ (ed) The instruments of psychiatric research. Wiley, Chichester, pp 271-304

6. Angold A, Erkanli A, Silberg J, Eaves L, Costello EJ (2002) Depression scale scores in 8-17-year-olds: effects of age and gender. J Child Psychol Psychiatry 43:1052-1063

7. Bakker MP, Ormel J, Verhulst FC, Oldehinkel AJ (2010) Peer stressors and gender differences in adolescents' mental health: the TRAILS study. J Adolesc Health 46:444-450

8. Barker ED, Arseneault L, Brendgen M, Fontaine N, Maughan B (2008) Joint development of bullying and victimization in adolescence: relations to delinquency and self-harm. J Am Acad Child Adolesc Psychiatry 47:1030-1038

9. Berger KS (2007) Update on bullying at school: science forgotten? Dev Rev 27:90-126

10. Bowker JC, Rubin KH, Buskirk-Cohen A, Rose-Krasnor L, Booth-LaForce C (2010) Behavioral changes predicting changes in perceived popular status. J Appl Dev Psychol 31:126133

11. Craig W, Harel-Fish Y, Fogel-Grinvald H, Dostaler S, Hetland J, Simons-Morton B, Molcho M, de Mato MG, Overpeck M, Due P, Pickett W, HBSC Violence \& Injuries Prevention Focus Group, HBSC Bullying Writing Group (2009) A cross-national profile of bullying and victimization among adolescents in 40 countries. Int J Public Health 54:216-224

12. Daviss WB, Birmaher B, Melhem NA, Axelson DA, Michales SM, Brent DA (2006) Criterion validity of the Mood and Feelings
Questionnaire for depressive episodes in clinic and non-clinic subjects. J Child Psychol Psychiatry 49:927-934

13. Dill EJ, Vernberg EM, Fonagy P, Twemlow SW, Gamm BK (2004) Negative affect in victimized children: the roles of social withdrawal, peer rejection, and attitudes toward bullying. J Abnorm Child Psychol 32:159-173

14. Harter S (1988) Manual for the self-perception profile for adolescents. University of Denver, Denver

15. Hawker DSJ, Boulton MJ (2000) Twenty years of research on peer victimization and psychosocial maladjustment: a meta-analytic review of cross-sectional studies. J Child Psychol Psychiatry 4:441-455

16. Hunter SC, Boyle JME, Warden D (2004) Help seeking amongst child and adolescent victims of peer-aggression and bullying: the influence of school-stage, gender, victimisation, appraisal, and emotion. Br J Educ Psychol 74:375-390

17. International Labour Office (1990) ISCO-1988: International Standard Classification of Occupations. International Labour Office, Geneva

18. Ivarsson T, Broberg AG, Arvidsson T, Gillberg C (2005) Bullying in adolescence: psychiatric problems in victims and bullies as measured by the youth self report (YSR) and the depression self-rating scale (DSRS). Nord J Psychiatry 59:365-373

19. Klomek AB, Marrocco F, Kleinman M, Schonfeld IS, Gould M (2007) Bullying, depression, and suicidality in adolescents. J Am Acad Child Adolesc Psychiatry 46:40-49

20. Klomek AB, Sourander A, Niemela S, Kumpulainen K, Piha J, Tamminene T, Almqvist F, Gould MS (2009) Childhood bullying behaviors as risk for suicide attempts and completed suicides: a population-based birth cohort study. J Am Acad Child Adolesc Psychiatry 48:254-261

21. Kumpulainen K, Räsänen E, Puura K (2001) Psychiatric disorders and the use of mental health services among children involved in bullying. Aggress Behav 27:102-110

22. Kumpulainen K (2008) Psychiatric conditions associated with bullying. Int J Adolesc Med Health 20:121-132

23. Kvernmo S, Heyerdahl S (1998) Influence of ethnic factors on behavior problems in indigenous Sami and majority Norwegian adolescents. J Am Acad Child Adolesc Psychiatry 37:743-751

24. Nansel TR, Craig W, Overpeck MD, Saluja G, Ruan J, The Health Behavior in School-aged Children Bullying Analyses Working Group (2004) Cross-national consistency in the relationship between bullying behaviors and psychosocial adjustment. Arch Pediatr Adolesc Med 158:730-736

25. Olweus D (1994) Annotation: bullying at school. Basic facts and effects of a school based intervention program. J Child Psychol Psychiatry 35:1171-1190

26. Perren S, Alsaker FD (2006) Social behavior and peer relationships of victims, bully-victims, and bullies in kindergarten. J Child Psychol Psychiatry 47:45-57

27. Roland E (2002) Bullying, depressive symptoms and suicidal thoughts. Educ Res 44:55-67

28. Ryan W, Smith DJ (2009) Antibullying programs in schools: how effective are evaluation practices? Prev Sci 10:248-260

29. Samm A, Tooding LM, Sisask M, Kõlves K, Aasvee K, Värnik A (2010) Suicidal thoughts and depressive feelings amongst Estonian schoolchildren: effect of family relationship and family structure. Eur Child Adolesc Psychiatry 19:457-468

30. Solberg ME, Olweus D, Endresen IM (2007) Bullies and victims at school: are they the same pupils? Br J Educ Psychol 77:441464

31. Sourander A, Jensen P, Rønning JA, Elonheimo H, Niemela S, Helenius H, Kumpulainen K, Piha J, Tamminen T, Moilanen I, Almqvist $\mathrm{F}$ (2007) Childhood bullies and victims and their risk of criminality in late adolescence. Arch Pediatr Adolesc Med $161: 546-552$ 
32. Sourander A, Rønning J, Brunstein-Klomek A, Gyllenberg D, Kumpulainen K, Niemela S, Helenius H, Sillanmaki BA, Ristkari T, Tamminen T, Moilanen I, Piha J, Almqvist F (2009) Childhood bullying behavior and later psychiatric hospital and psychopharmacologic treatment. Arch Gen Psychiatry 66:1005-1012

33. Sund AM, Larsson B, Wichstrøm L (2001) Depressive symptoms among young Norwegian adolescents as measured by the Mood and Feelings Questionnaire (MFQ). Eur Child Adolesc Psychiatry $10: 222-229$
34. Thunfors P, Cornell D (2008) The popularity of middle school bullies. J Sch Violence 7:65-82

35. Wichstrøm L (1995) Harter's self-perception profile for adolescents: reliability, validity and evaluation of the question format. J Pers Assess 65:100-116

36. Wood A, Kroll L, Moore A, Harrington R (1995) Properties of the Mood and Feelings Questionnaire in adolescent psychiatric outpatients: a research note. J Child Psychol Psychiatry 36:327-334 